\title{
FUENTES PARA LA HISTORIA DE LA TIERRA PUBLICA DEL TERRITORIO DEL CHACO
}

\author{
Sources for the history of public lands in the Territory of Chaco
}

\section{Adrián A. Almirón}

\section{Resumen}

El Instituto de Colonización de la provincia del Chaco resguarda numerosos expedientes que nos posibilitan conocer la historia de la tierra en el Chaco desde la formación del Territorio hasta la actualidad. Entre esa documentación destacamos las mensuras y las inspecciones. Ambas tienen un gran valor para la reconstrucción histórica porque constituyen un detallado registro sobre el poblamiento de las tierras fiscales y la creación de colonias y pueblos.

El presente trabajo tiene como objeto la descripción del archivo del instituto de Colonización. Para ello, primeramente, especificaremos el funcionamiento de la repartición destacando las secciones que posee, señalando asimismo el lugar donde se encuentran los expedientes y las contribuciones al conocimiento histórico que este tipo de fuentes puede brindar al estudio de la tierra pública.

$$
<\text { Instituto de Colonización }><\text { Chaco }><\text { tierras }>
$$

\begin{abstract}
The Instituto de Colonización of the Chaco province preserves numerous files that allow us to know the history of the land in the Chaco since the formation of the Territory until the present. Among these documents, the surveying and inspections should be highlighted. They are valuable for reconstructing the past because they constitute a detailed record of the public land settlements, and of the colonies and villages creation.

This paper aims to describe the archive of the Instituto de Colonización with special focus on its sections. The place where the files are stored is also described. Finally, the contributions of such sources to the historical study of the public land are mentioned.
\end{abstract}

$<$ Institute of colonization $><$ Chaco $><$ lands $>$

Recibido: 31/03/2014 // Aceptado: 06/06/2014

* Licenciado en Historia, Becario Co financiado Tipo II CONICET/UNNE, IIGHI-UNNE/CONICET,

almiron.historia@gmail.com 


\section{Introducción}

El estudio de la tierra pública ha sido abordado desde diversas fuentes. En esta ocasión quisiéramos destacar el uso de las fuentes estatales, éstas nos aportan una mirada minuciosa sobre las distintas actividades de los actores que integran el conjunto social pero también nos permiten indagar sobre como representaba el Estado esos actores, por medio de sus intermediarios oficiales.

Reconocer el criterio intencional de estos documentos es fundamental para elaborar cuestionamientos sobre sus descripciones, estas "fuentes voluntarias" se caracterizan por constituir una memoria oficial de la sociedad. Estas nos permiten tener una aproximación al imaginario de la época al cual debemos contrastarlo y someterlo a prueba con otras fuentes de información (Arostegui, 2001).

La generación de información por parte del personal del Estado nos lleva a reflexionar sobre la elaboración de un saber que se proyecta como practica estatal en el terreno, evidenciándose esto en la organización de los diversos grupos humanos y en la regulación de las forma de vida (Regina de Mendonca, 2011: 32). Estos documentos nos habilitan a tener una mirada sobre las labores de los técnicos del Estado y nos brindan información fundada en la observación directa, de las condiciones en que se desarrolló el proceso de ocupación en el Territorio del Chaco.

El presente trabajo tiene como objetivo hacer una descripción sobre los documentos que se encuentran en el Instituto de Colonización de la Provincia del Chaco, teniendo como finalidad no sólo exponer la valiosa información que contiene dicha repartición provincial sino también reflexionar sobre el uso de esas fuentes para la historia regional y local.

\section{Información General}

El Ministerio de Agricultura fue creado en 1898 durante la segunda presidencia de Julio Argentino Roca, el principal objetivo de esta repartición fue lograr modernizar y organizar las distintas explotaciones pampeanas y extra-pampeanas. Fue de especial interés para el gobierno la administración de la tierra pública, por lo que el nuevo ministerio tenía bajo su dependencia a la "Dirección General de Tierras y Colonias".

Esta Dirección tenía a cargo la administración de la tierra pública. La cual estaba encargada de mensurar y subdividir las tierras fiscales para la creación de colonias y pueblos, tarea de gran importancia para el modelo de colonización oficial adoptada. Desde 1903 con la ley 4167 se instauró la exploración previa de la tierra. Con esta ley se intentó evitar la formación de latifundios y propiciar la creación de colonias.

$\mathrm{Su}$ sede central se encontraba en Buenos Aires, pero con el fin de llevar adelante una mejor administración del suelo, se instalaron distintas oficinas en los Territorios Nacionales. En Chaco la primera oficina se creó en 1923 en Resistencia. Con el tiempo la principal dependencia local se trasladaría a Presidencia Roque Sáenz Peña. Junto con esta jefatura se crearon nuevas oficinas en Resistencia, Charata, Tres Isletas, Castelli y Las Breñas. Los empleados de estas oficinas tenían entre sus obligaciones llevar a 
cabo las inspección de la tierra y los bosques nacionales; entregar a los colonos sus títulos provisionales, definitivos o contratos formulados, también cumplían la tarea de recaudar impuestos y de elevar en consulta los expedientes que debían ser resueltos a nivel nacional.

En 1945 mediante el decreto 32.404 la Dirección se convirtió en la Dirección General de Tierras y Bosques, integrando la administración de la tierra pública y el bosque fiscal.

Hacia 1951 el Territorio Nacional del Chaco se provincializó y su administración se reestructuró. El organismo se denominó "Dirección de Tierras y Colonización" dependiente del gobierno de la provincia y tuvo como principal objetivo la organización interna, el ordenamiento de la documentación sobre tierras que recibía de la nación y al mismo tiempo, acelerar la entrega de títulos y organizar nuevas colonias. Desde 1954 toda la documentación administrada por la repartición nacional pasó a esta Dirección. Desde entonces, la provincia cuenta con documentación valiosa sobre la administración de la tierra pública que comprende desde 1878.

Bajo el gobierno del Coronel Roberto Oscar Mazza en 1972, se creó el Instituto de Colonización por la ley 1.094. Este organismo provincial, ha centralizado las decisiones sobre la política de tierras hasta el presente. En los últimos años, la actual gestión del Ejecutivo propuso redefinir este organismo; sin embargo, no se ha producido ningún cambio sobre esta institución. Por otra parte, el Instituto desde el 2010 trabaja con un sistema informático, denominado K-ren, que sistematiza toda la información, y tiene el objetivo dar mayor efectividad a los trámites administrativos.

\section{Colección de documentos}

En el Instituto de Colonización se encuentra un valioso número de fuentes que nos posibilitan estudiar la ocupación del suelo. Entre los más apreciables destacamos las inspecciones y las mensuras de tierras.

Las mensuras son una expresión cabal del poder estatal (Pro Ruiz, 2011: 13). Indagar sobre los trabajos de campo de los agrimensores nos posibilita aproximarnos a las concepciones de la sociedad y del territorio, y nos permite estudiar la vinculación que existió entre el Estado y la sociedad civil. Tal como lo sostiene Pro Ruiz sobre la importancia de las mensuras en la constitución de los Estados Nacionales, la tierra se convierte en el escenario en donde se evidencia la aplicación del poder del Estado. La mensura de la tierra se convierte en un instrumento vital para gobernar (Pro Ruiz, 2011: 24).

De esta forma, estos documentos son claves para desarrollar el estudio de la tierra. La información que consta en estas fuentes detalla sobre las condiciones agroeconómicas del suelo, la población residente, la fecha de ocupación, la producción agropecuaria y los antecedentes sobre la creación de un pueblo o colonia fiscal. El resultado de esta indagación debía ser convertido en un informe que era remitido a la Dirección General de Tierras, a fin de que ésta pudiera definir las medidas del caso. 
En cuanto a las inspecciones de tierras estas tenían el objetivo de informar al organismo público, sobre el estado legal de las posesiones en la tierra fiscal, libre o concedida. En el caso de encontrarse concedida, los inspectores informaban sobre el cumplimiento de las obligaciones contraídas por los concesionarios. Estos funcionarios también notificaban a las autoridades correspondientes la situación de los pobladores y las necesidades económicas de los Territorios. Los informes de los inspectores contienen datos sobre la vivienda, las mejoras realizadas en el terreno y el concepto que el poblador tenía a los ojos del experto.

En este sentido las mensuras y las inspecciones de tierras nos posibilitan comprender una doble dinámica del proceso de colonización: en primer lugar, nos permiten acceder a un registro detallado de cada parcela ocupada por los productores; que posibilita el análisis de la evolución demográfica, económica y social de una colonia o pueblo. En segundo lugar, el trabajo con este tipo de fuentes nos habilita a examinar el comportamiento de estos expertos en el terreno, logrando con esto aproximarnos a las apreciaciones personales de cada uno de ellos sobre las distintas perspectivas que cada uno tenía sobre la realidad, lo cual nos sirve como indicio para comprender los objetivos propuestos por el Estado y sobre la autonomía profesional que tenían dentro de la repartición estatal (González Leandri, 2012).

El Instituto se encuentra en el $5^{\circ}$ piso de la Casa de Gobierno y está subdividido en distintas reparticiones. Los documentos señalados anteriormente se encuentran en la sección de Topografía y Cartografía de la Dirección del Archivo Central. En ambos lugares para realizar la consulta de la documentación, debe solicitarse autorización al Director del Instituto. El horario de consulta es desde las 7,30 hs hasta las 12,30 hs. todos los días hábiles, salvo en el receso de enero.

La Sección de Topografía cuenta con una colección de expedientes que contienen duplicados de mensuras efectuadas en el Territorio Nacional y en la Provincia del Chaco. Es una oficina donde se encuentran los agrimensores y el personal técnico, quedando un reducido espacio para trabajar, se cuenta con una mesa de trabajo que es utilizada por los topógrafos, también se cuenta con una fotocopiadora, aunque solamente se utiliza para uso de la oficina. Cada uno de esos duplicados contiene un plano de mensura, cuyos originales o copias se conservan en una mapoteca general, de esta misma sección. Un sello y un número en el expediente permiten buscar el plano correspondiente.

Por su parte la Dirección de Archivo Central fue creada en el 2010, mediante el decreto 204/10. Esta nueva sección que depende directamente del gerente general y contiene principalmente la documentación relacionada con las inspecciones y estudios agroeconómicos. Debido al gran número de expedientes el espacio físico de la sede central no es suficiente, por este motivo buena parte del archivo se encuentra en el taller mecánico del Instituto, ubicado en la calle Parodi y Arturo Illia.

Para sistematizar la búsqueda de la información, la Dirección de Archivo cuenta con una sección denominada "casillero", donde se hallan fichas ordenadas cronológicamente, por departamentos y colonias. En los últimos años este sistema ha sido lentamente remplazado por el sistema informático K-ren que permite tener un 
registro más rápido sobre un lote o sección determinada. La Dirección se encuentra conducida por el archivista y bibliotecario Oscar Núñez quien junto con un grupo de trabajo han logrado ordenar un cumulo de documentación que se encontraba dispersa y sin acceso al público.

El Archivo Central además cuenta con una biblioteca especializada para los técnicos. De esta forma el archivo está compuesto de la siguiente documentación

- Libros especializados sobre agronomía: Estas son obras generales de agronomía que son consultadas por los técnicos del instituto.

- Recopilación de leyes del código civil y comercial: Estas son compilaciones de las normativas de la época. Esta colección se encuentra desde 1930 en adelante hasta la actualidad.

- Mapoteca posee una colección de cartografías desde 1955 en adelante.

- Resoluciones-Memorándums-Dictámenes - 1960 en adelante.

- Estudios agroeconómicos desde 1930 hasta el 2012. Este material se encuentra sin catalogación.

Estos estudios son de gran relevancia por la información que contiene, se caracterizan por ser inspecciones de terrenos considerados previamente por el Estado como libres, donde el objetivo era lograr detallado un registro del suelo a fin de poder poblarlo. Es importante esta exploración dado que mediante estos estudios se realizaron la creación de las colonias y pueblos en el Territorio del Chaco.

En el taller por su parte se encuentran documentos vinculados con el funcionamiento administrativo del Instituto de Colonización. Entre ellos destacamos:

- Fichas personales de colonos que registran el lugar en el que se encuentran, el año de llegada, la composición familiar. Estas fichas se ubican en paquetes y no contienen un orden cronológico, ni de colonias o pueblos.

- Boleto de pago de impuestos de tierras, están desordenadas y sin catalogación.

- Carpetas y cuadernos administrativos desde 1994.

- Expedientes escriturados y simples desde 1878.

Los expedientes escriturados y simples son sumamente interesantes por la información que nos proporcionan. En líneas generales tratan sobre el pedido del concesionario para adquirir su título de propiedad e incluyen la inspección en la parcela para establecer si dicho pedido debía ser atendido. El final del expediente consta con la aprobación o desaprobación de la solicitud y en algunos casos se incluye el título de propiedad.

En el caso de los expedientes simples podemos encontramos con información sobre el funcionamiento de la Dirección General de Tierras, la elaboración de mensuras e inspecciones en el terreno o sobre la situación de los colonos que residían en el Territorio. Contienen datos de primera mano de los expertos y mediante su seguimiento 
se pueden registrar las decisiones de las instituciones encargadas de llevar a cabo el proceso de colonización.

Estos documentos se encuentran resguardados en paquetes numerados, cada uno de ellos contiene entre 40 a 45 expedientes. El archivo tiene más de 2000 paquetes. Es importante señalar que la documentación reunida en cada paquete, no se encuentra agrupada por año o por lugar de trabajo.

En los últimos años se ha realizado un reacondicionamiento de los paquetes, pero dicha tarea quedo inconclusa. Por otro lado, también se encuentran expedientes de otros Territorios Nacionales como Misiones, Chubut, o en un caso excepcional sobre tierras en Córdoba.

En el taller no hay espacio para trabajar, no se cuenta con centro de copiado, se debe destacar que para realizar un registro fotográfico de los documentos, debe pedirse un permiso al director del Instituto. No obstante a estas dificultades se debe destacar que los documentos en gran medida se encuentran bien resguardados y conservados, lo cual posibilita el trabajo de registro sin ningún inconveniente.

\section{Consideraciones finales}

La documentación albergada en el Instituto de Colonización resguarda la información más minuciosa sobre la administración de la tierra pública en el Chaco. Estas fuentes nos permiten una aproximarnos al conocimiento de la ocupación del suelo, el origen y desarrollo de pueblos y colonias así como también de los conflictos entre los pobladores del Chaco y el poder nacional en relación con el dominio del suelo.

El análisis sistemático estas fuentes nos abre nuevas posibilidades sobre la historia del Territorio teniendo en cuenta que en gran medida aún no se conoce el total de la documentación que el propio instituto posee.

\section{Bibliografía}

Aróstegui, Julio. 2001. La investigación histórica: teoría y método. Barcelona, Crítica Bandieri, Susana y Blanco, Graciela. 2009. "Política de tierras públicas en los Territorios Nacionales: entre la norma y la práctica”. En: Blanco, Graciela y Banzato, Guillermo (eds.): La cuestión de la tierra publica en Argentina. A 90 años de la obra de Miguel Ángel Carcano, Rosario, Prohistoria, pp. 163-199.

Beck, Hugo. 2008. "Geografía Económica del Chaco y Formosa del Ingeniero Alberto Carlos Muello: obra de consulta de productores de antaño y de investigadores actuales". En: Revista de la Junta de Estudios Históricos del Chaco, Resistencia;A\&A Impresiones, pp. 121-140.

2008. "Guías del Chaco y de Formosa. Útiles informaciones del Pasado, valiosas fuentes para investigaciones actuales". En: Folia Histórica del Nordeste, $N^{\circ}$ 17, IIGHI-CONICET, Resistencia, pp. 181-190. 
Brohoslavsky Ernesto, Soprano Germán. 2010. Un Estado con rostro humano. Funcionarios e instituciones estatales en Argentina (desde 1880 hasta la actualidad), Buenos Aires, Prometeo.

Girbal-Blacha, Noemí. 2007. "Vigencia de las tramas regionales". En: Graciano Osvaldo y Lazzaro Silvia (comp). La Argentina Rural del Siglo XX, Buenos Aires, La Colmena, pp. 41-51.

González- Leandri, Ricardo. 2011. "Gobernabilidad y autonomía. Dos cuestiones claves para el estudio de los profesionales y expertos". En: Revista Ecuador Debate [En línea] URL: http://www.flacsoandes.edu.ec/dspace/handle/10469/3998

Jacob, Omar Ricardo. 2006. Castelli. Historia de la localidad, colonias y parajes, en el ámbito del Noroeste Chaqueño (1928-1995), Corrientes, Moglia ediciones.

Regina de Mendoca, Sonia. 2011. "Tecnología, burocracia y agricultura en Latinoamérica contemporánea”. En: Ruffini Martha y Blacha Luis. Burocracia, tecnología y agro en espacios marginales, Rosario, Prohistoria, pp. 31-44.

Miranda, Guido.1979. Los orígenes de las Breñas, Departamento Editorial Eduardo Velardez, Resistencia.

2005. Tres Ciclo Chaqueños (Crónica histórica regional). Cuarta edición, Librería la Paz, Resistencia.

Meader, Ernesto. 1978. "Relevamiento de los fondos documentales de los archivos de la región nordeste argentina de Asunción del Paraguay". En: Revista de Estudios Regionales, Centro de estudios regionales del Nordeste Argentino, Vol. III, CONICET-FUNDANORD, Corrientes.

Pro Ruiz, Juan. 2011. "Mensura, catastro y construcción estatal”. En: Caravaglia Juan Carlos y Gautreau (Edit.) Mensurar la tierra, controlar el territorio. América Latina, siglos XVIII-XIX. Prohistoria, Rosario, pp. 13-26.

Schaller, Enrique Cesar. 2010. "Política de tierras en la Provincia del Chaco (19541971)". En: Mari, Oscar; Mateo Graciela y Valenzuela, Cristina (Comp.). Territorio, poder e identidad en el agro Argentino, Buenos Aires, Imago Mundi, pp. 41-64. 
Almirón. Fuentes para la historia de la tierra pública del Territorio del Chaco

\section{ANEXO}

Organigrama del Instituto de Colonización decreto $N^{\circ} 204$

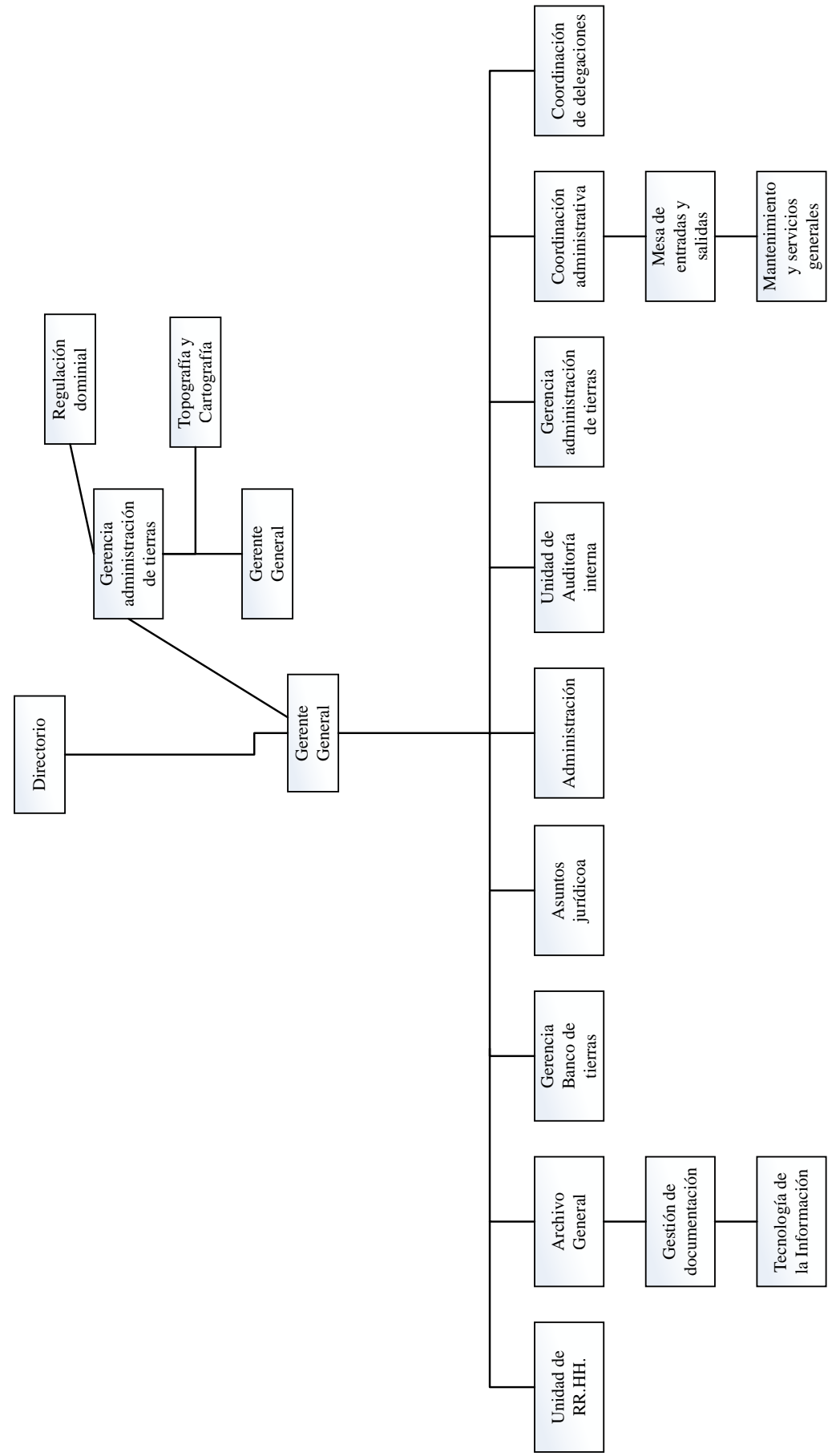

Fuente: Elaborado en base al Decreto $N^{\circ} 204 / 10$ 